\title{
Correction to: Differential Geometry of Curves and Surfaces
}

\section{Correction to:}

\author{
S. Kobayashi, Differential Geometry of Curves \\ and Surfaces, Springer Undergraduate Mathematics \\ Series, https://doi.org/10.1007/978-981-15-1739-6
}

The original version of the book was inadvertently published with errors in equations and text on the following pages: 009, 013, 017, 020, 026, 062, 071, 104, 121, $124,131,133,139$, and 148. These have now been updated and approved by the author.

The updated version of these chapters can be found at https://doi.org/10.1007/978-981-15-1739-6_1 https://doi.org/10.1007/978-981-15-1739-6_2 https://doi.org/10.1007/978-981-15-1739-6_3 https://doi.org/10.1007/978-981-15-1739-6_4 https://doi.org/10.1007/978-981-15-1739-6_5 